\title{
PEENCANAAN DAN PENGENDALIAN BAHAN BAKU KURSI KAYU BENGKOK DENGA METODE MATERIAL REQUIREMENT PLANNING (MRP) DI CV. ADIL AMBARAWA
}

\author{
Khairun Nisa1), Rindra Yusianto ${ }^{2)}$, Jazuli ${ }^{3)}$ \\ Program Studi Teknik Industri \\ Fakultas Teknik \\ Universitas Dian Nuswantoro Semarang \\ Jalan Nakula I No. 5-11 Semarang 50131 \\ Telp: (024) 3517261, fax: (024) 3520165
}

E-mail: nisa.kn50@gmail.com ${ }^{1)}$; rindra@dsn.dinus.ac.id ${ }^{2)}$; jazuli@dsn.dinus.ac.id ${ }^{3}$

\begin{abstract}
CV.Adil Ambarawa is a manufacturing company engaged in the manufacture of furniture. One of the furniture that is produced is the Crooked Wooden Chair. The shape of this chair is unique and bent that makes consumers interested and happy with this furniture product. The type of production at the company is a product made in accordance with the request (make to order). In planning and controlling raw materials, companies experience problems because they have not carried out a proper planning in determining raw material requirements. To help problems that occur in CV. Adil Ambarawa, then applied a Material Requirement Planning (MRP) method that can assist companies in planning and controlling raw materials appropriately and efficiently. The costs incurred by the company in procuring raw materials for one year were IDR 431,165,000, while using the MRP with the lot sizing Periodic Order Quantity (POQ) technique, the company spent IDR 349,515,467
\end{abstract}

Keywords: Material Requirement Planning, Lot Sizing, Material Planning

\begin{abstract}
Abstrak
CV. Adil Ambarawa merupakan perusahaan manufaktur yang bergerak dalam pembuatan furniture. Salah satu furniture yang dihasilkan adalah Kursi Kayu Bengkok. Bentuk kursi ini yang unik dan bengkok yang membuat konsumen tertarik dan senang dengan produk mebel ini. Jenis produksi pada perusahaan tersebut adalah produk produksi sesuai dengan permintaan (make to order). Dalam melakukan perencanaan dan pengendalian bahan baku, perusahaan mengalami kendala karena belum dilakukannya suatu perencanaan yang tepat dalam menentukan kebutuhan bahan baku. Untuk membantu masalah yang terjadi pada CV. Adil Ambarawa, maka diterapkan suatu metode Material Requirement Planning (MRP) yang dapat membantu perusahaan dalam melakukan perencanaan dan pengendalian bahan baku secara tepat, dan efisien. Biaya yang dikeluarkan perusahaan dalam melakukan pengadaan bahan baku selama satu tahun sebesar Rp 431.165.000, sedangkan dengan menggunakan MRP dengan teknik lot sizing Periodic Order Quantity (POQ), perusahaan mengeluarkan biaya sebesar Rp 349.515.467.
\end{abstract}

Kata Kunci: Material Requirement Planning, Teknik Lot Sizing, Perencanaan Bahan Baku 


\section{Applied Industrial Engineering Journal}

Vol.04, No. 01, Juni 2020, pp. 09 19

ISSN 2614-235X (Printed)

ISSN 2615-3033 (Online)

http://publikasi.dinus.ac.id/index.php/aiej/index

\section{Pendahuluan}

CV. Adil Ambarawa merupakan perusahaan manufaktur yang bergerak dalam pembuatan furniture atau Meubel. Produk-produk yang dihasilkan juga sangat beragam dari mulai almari, kursi, meja, kaca hias, buffet dan dll. Banyaknya produk yang dihasilkan tentunya harus adanya pengelolaan sistem persediaan yang baik. Berdasarkan pengamatan yang dilakukan pada CV Adil Ambarawa, proses produksi pada perusahaan tersebut adalah dependent atau produk produksi sesuai dengan permintaan (make to order). Pada penelitian ini produk yang digunakan adalah produk dari CV. Adil Ambarawa yang miliki jumlah permintaan yang paling banyak.

Perusahaan ini belum menerapkan atau memiliki sistem perencanaan kebutuhan material yang baik, sehingga dalam proses produksinya sering terjadi keterlambatan produksi, dari mulai bahan baku dipesan kemudian diproses sampai dengan proses finishing terkadang mengakibatkan produk yang dipesan tidak jadi sesuai dengan waktu yang ditentukan karena kekurangan stock persediaan material (stock out). Hal ini disebabkan karena belum adanya perhitungan waktu tenggang atau (lead time) untuk pembuatan suatu produk sampai waktu tenggang untuk masing-masing komponen pembentuk produk tersebut. Selain itu, juga sering terjadi kelebihan produksi pada tahun 2017 yang melebihi jumlah permintaan yang ditargetkan. Hal ini dikarenakan pembelian bahan baku yang kurang terjadwal dan terkendali sehingga menyebabkan overstock dan over production. Meskipun melebihi permintaan, keadaan tersebut menimbulkan biaya simpan material dan produk di gudang oleh CV Adil sehingga mengurangi efisiensi biaya produksi.

Berdasarkan latar belakang permasalahan diatas, penelitian ini membahas tentang perencanaan kebutuhan bahan baku yang akan digunakan untuk membuat pesanan produksi dan pembelian. Serta mengatur aliran bahan baku dan persediaan sehingga sesuai dengan jadwal produksi untuk produk akhir sehingga berjalan dengan baik dengan menggunakan metode MRP sebagai sebuah teknik permintaan terikat yang menggunakan daftar kebutuhan bahan, persediaan, penerimaan yang diperkirakan, dan jadwal produksi induk untuk menentukan kebutuhan material.

Tujuan penelitian yaitu merancang perencanaan dan pengendalian bahan baku kursi kayu bengkok dengan menggunakan metode MRP pada CV. Adil Ambarawa.

\section{Metode Penelitian}

Pada bab ini penulis akan menjelaskan tahapan-tahapan atau proses berpikir dalam pemecahan masalah dengan tujuan agar penelitian yang penulis lakukan dalam penyusunan tugas akhir ini lebih terarah dan sistematis. Penelitian dilaksanakan di perusahaan CV. Adil yang berlokasi di Jalan Brigjen Sudiarto No 37 Ambarawa, Kabupaten Semarang, Jawa Tengah. Penelitian ini dilakukan pada bulan Januari 2019. Obyek penelitian hanya terbatas pada kebutuhan bahan baku pada proses produksi kursi kayu bengkok.

\section{Pengumpulan Data}

Sumber data primer dari penelitian ini diambil dari studi lapangan, wawancara dengan pekerja. Sedangkan sumber data sekunder didapat dari internet atau buku tentang objek yang diteliti.

\section{a. Data Primer}

Data primer adalah data yang diperoleh dari pengamatan dan penelitian langsung terhadap objek penelitian dilapangan yaitu kondisi actual dari lantai produksi. Adapun data yang dikumpulkan dengan cara ini adalah urutan proses produksi. Selain itu juga mengenai leadtime material yang didapatkan dari hasil wawancara dengan pihak perusahaan.

b. Data Sekunder

Data sekunder adalah data yang diperoleh dari sumber tidak langsung yang biasanya berupa data dolumentasi dan arsip resmi. Data yang telah diteliti dan dikumpulkan tentang produk kursi kayu bengkok adalah sebagai berikut :

- Data pemesanan produk kursi kayu bengkok dari tahun 2016 - 2018. 
- Data struktur produk kursi kayu bengkok (Bill of Material)

- Data persediaan komponen kursi kayu bengkok

- Harga beli, biaya pesan dan biaya inventori dari material untuk membuat kursi kayu bengkok

Langkah-langkah alur penelitian yang dilakukan adalah sebagai berikut:

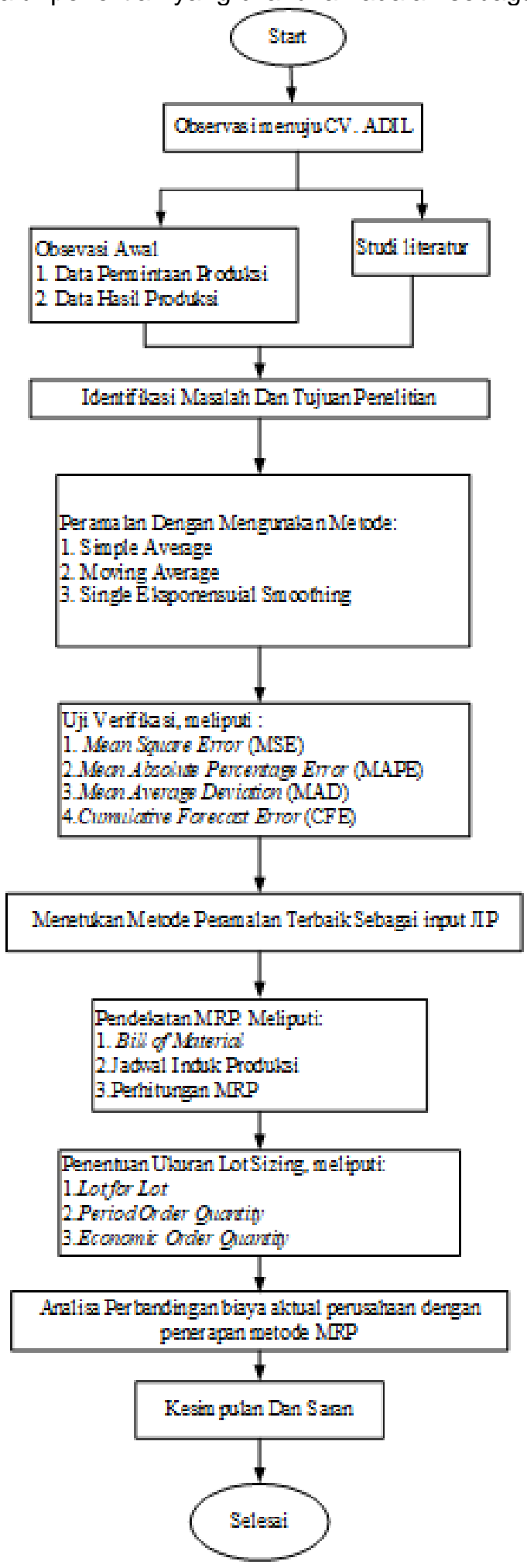

Gambar 1. Alur Penelitian 
2011)

Tahap peramalan yang dilakukan berdasarkan langkah-langkah sebagai berikut (Hartini,

1. Penentuan plot data

2. Penentuan metode peramalan

3. Perhitungan error dari tiap peramalan

4. Penentuan metode terbaik berdasarkan nilai error

5. Validasi metode terpilih

6. Penentuan Jadwal Induk Produksi (JIP)

Kemudian pengolahan data dilanjutkan dengan perhitungan MRP. Heizer dan Render (2005:176-179) menyatakan bahwa sistem MRP adalah cara yang sangat baik untuk menentukan jadwal produksi dan kebutuhan bersih. Menurut Purnomo (2004:108) secara umum MRP mempunyai tujuan yang dapat dijabarkan sebagai berikut:

1. Meminimalsasikan persediaan

2. Mengurangi resiko keterlambatan produksi atau pengiriman

3. Menentukan pelaksanaan rencana pemesanan

4. Menentukan penjadwalan ulang

a. Netting

Langkah - langkah perhitungan MRP adalah sebagai berikut (Hendra, 2009):

Kebutuhan Bersih (NR) dihitung sebagai nilai dari Kebutuhan Kotor (GR) minus Jadwal Penerimaan (SR) minus Persediaan di tangan $(\mathrm{OH})$. Kebutuhan Bersih dianggap nol bila NR lebih kecil dari atau sama dengan nol.

b. Lotting

$$
\mathbf{N R}=\mathbf{G R}-\mathrm{SH}-\mathrm{OH}
$$

Langkah ini bertujuan menentukan besarnya pesanan individu yang optimal berdasarkan hasil dari perhitungan kebutuhan bersih. Langkah ini ditentukan berdasarkan teknik lotting/lotsizing yang tepat. Parameter yang digunakan biasanya adalah biaya simpan dan biaya pesan.

c. Offsetting

Langkah ini bertujuan agar kebutuhan komponen dapat tersedia tepat pada saat dibutuhkan dengan memperhitungkan lead time pengadaan komponen tersebut. Rencana pemesanan didapat dengan cara menggabungkan saat awal tersedianya ukuran lot (lot size) yang diinginkan dengan besarnya leadtime. Leadtime ini sama dengan besarnya waktu saat barang mulai dipesan atau diproduksi sampai barang tersebut siap untuk dipakai.

d. Explosion

Langkah ini merupakan proses perhitungan kebutuhan kotor untuk tingkat item (komponen) pada level yang lebih rendah dari struktur produk yang tersedia.

\section{Hasil dan Analisis}

\subsection{Forecasting}

Berikut ini merupakan tahapan peramalan yang dilakukan:

a. Menentukan Plot Data

Plot data permintaan produk kursi kayu bengkok selama tahun 2016 sampai tahun 2018 pada gambar 2.

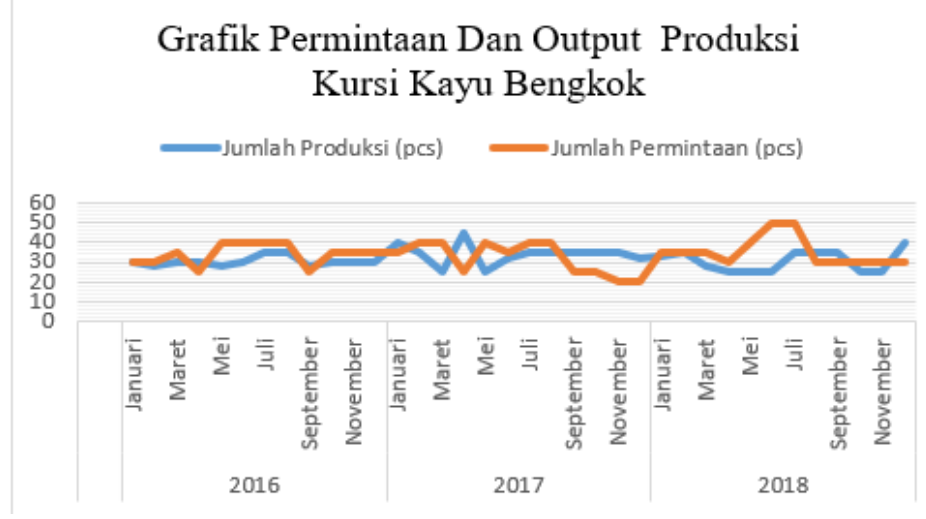

Gambar 2. Grafik Data Permintaan Produk Kursi Kayu Bengkok 
Pola data yang cocok dalam mengambarkan data permintaan kursi kayu bengkok ialah pola siklis atau dapat dikatakan data yang tidak mengalami kecendurungan naik atau turun (trend line), maka metode peramalan yang dapat digunakan ialah metode Moving Average dan Exponential Smoothing (Makridakis, 1988). Sehingga metode peramalan yang digunakan yaitu Simple Average, Moving Average, dan Single Exponential Smoothing.

b. Perhitungan Metode Peramalan

1. Metode Simple Average

Pada metode ini perhitungan ditentukan oleh banyaknya data jenis permintaan yang diambil dan dibagi berapa data perbulannya, sehingga muncul rata-rata peramalan yang dapat menjadi acuan bulan depan. Berdasarkan perhitungan dengan menggunakan metode SA yang dilakukan didapatkan peramalan untuk 12 pertiode ke depan yaitu ratarata 35 pcs kursi kayu bengkok.

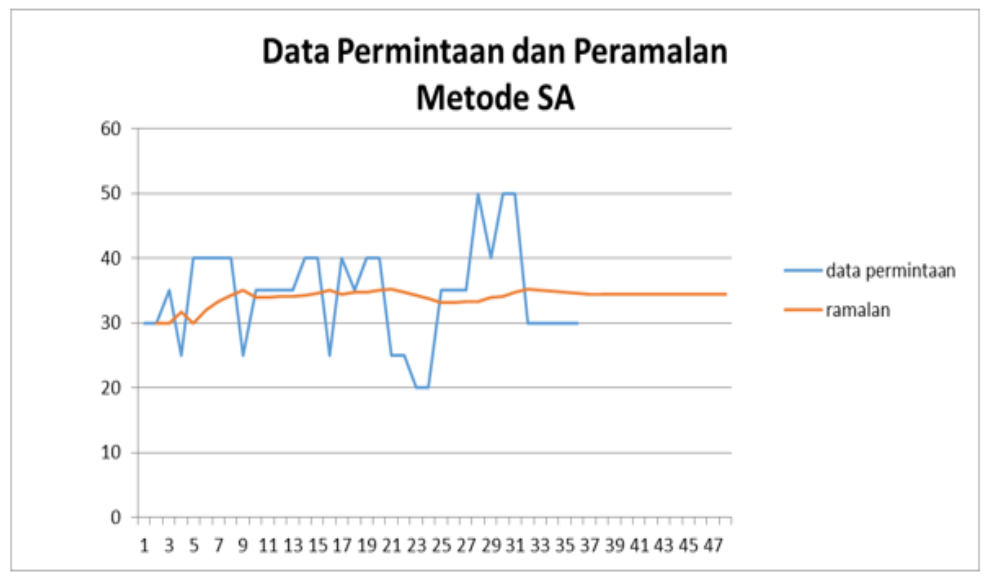

Gambar 3. Peramalan Menggunakan Metode SA

2. Metode MA

Perhitungan peramalan pada metode ini hampir sama dengan metode diatas. Untuk mendapatkan hasil perhitungan dengan cara menjumlahkan keseluruhan dari semua data periode waktu yang diperhitungkan dengan dengan jumlah rata-rata bergerak. Perhitungan peramalan pada periode sebelumnya harus dihilangkan untuk mengetahui peramalan periode selanjutnya.

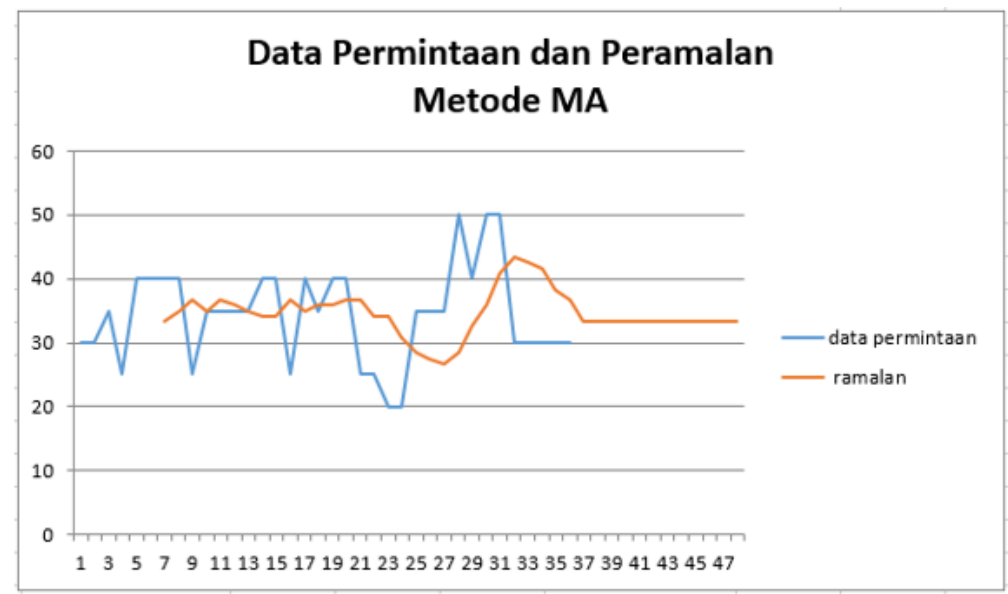

Gambar 4. Peramalan Menggunakan Metode MA

Berdasarkan perhitungan dengan menggunakan metode MA yang dilakukan didaptakan peramalan untuk 12 pertiode ke depan yaitu rata-rata 34 pcs kursi kayu bengkok. 
3. Metode SES

Perhitungan peramalan pada metode ini, maka langkah awal yang dilakukan adalah menentukan a (konstanta pemulusan).

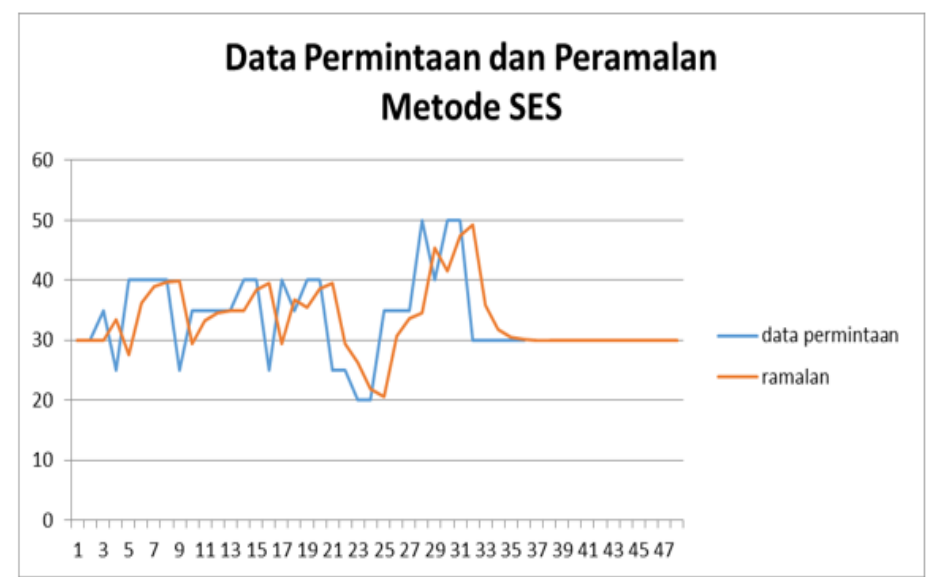

Gambar 5. Peramalan Menggunakan Metode SES

Penentuan besarnya nilai $\alpha$ dilakukan dengan ketentuan bahwa semakin bergejolak, nilai a yang dipilih harus semakin tinggi menuju ke nilai satu dan apabila semakin stabil, nilai $\alpha$ yang dipilih harus semakin kecil menuju ke nilai 0 . Nilai $\alpha$ yang digunakan adalah 0,7 yang didapatkan dari perhitungan.

Berdasarkan perhitungan dengan menggunakan metode SES yang dilakukan didaptakan peramalan untuk 12 pertiode ke depan yaitu rata-rata 31 pcs kursi kayu bengkok.

c. Verifikasi Atau Perhitungan Error Dari Tiap Peramalan

Verifikasi atau perhitungan error dilakukan dengan menggunakan 5 metode yaitu Mean Absolute Deviation (MAD), Cumulative Forecast Error (CFE), Mean Square Error (MSE), Mean Absolute Percentage Error (MAPE), dan Tracking signal.

Berikut ini merupakan table rekapitulasi perhitungan error dari 3 metode peramalan yang digunakan:

Tabel 1. Rekapitulasi Perhitungan Error

\begin{tabular}{|c|c|c|c|c|c|}
\hline Metode & MAD & CFE & MSE & MAPE & $\begin{array}{c}\text { Tracking } \\
\text { Signal }\end{array}$ \\
\hline SA & 6,4 & 26,9 & 62,4 & 0,2 & 4,2 \\
\hline MA & 7,9 & - & 85,7 & 0,2 & $-1,8$ \\
\hline SES & 5,7 & 0,07 & 61,6 & 0,1 & 0,01 \\
\hline Terbaik & SES & SES & SES & SES & SES \\
\hline \multicolumn{6}{|c}{ Sumber: Olah data, 2019 } \\
\hline
\end{tabular}

Dari tabel 1, dapat diketahui bahwa metode peramalan terbaik yaitu metode Single Exponential Smoothing. Sebagai pertimbangan dalam penentuan metode terbaik dilakukan analisa pada grafik antara data permintaan dan ramalan antara kedua metode tersebut. Pada grafik metode SES (gambar 5) antara data permintaan dan ramalan memiliki pola data yang hampir sama. Selain itu, nilai tracking signal yang positif menunjukkan bahwa nilai aktual permintaan lebih besar daripada ramalan, sedangkan tracking signal yang negatif berarti nilai aktual permintaan lebih kecil daripada ramalan. Suatu tracking signal disebut baik apabila memiliki CFE yang rendah dan mempunyai positive error yang sama banyak atau seimbang dengan negative error sehingga pusat dari tracking signal mendekati nol. Dengan kata lain, peramalan akan semakin bagus jika nilai error nya mendekati nol. Nilai tracking signal yang telah dihitung maka selanjutnya dapat dibangun peta control untuk melihat sebaran dan pergerakan data dari nilai tracking signal tersebut. Nilai tracking signal ini sebaiknya 
maksimum \pm 4 sebagai batas pengendaliannya. Nilai yang didapatkan melebihi batas maksimum tersebut, artinya model peramalan perlu ditinjau kembali karena akurasi peramalan tidak dapat diterima.

d. Validasi Metode Terpilih

Validasi dilakukan dengan memetakan nilai error dari metode terpilih dan melihat pergerakan errornya. Jika nilai error berada pada batas toleransi, maka metode dinyatakan valid. Berikut ini merupakan hasil dari validasi nilai error menggunakan peta Moving Range:

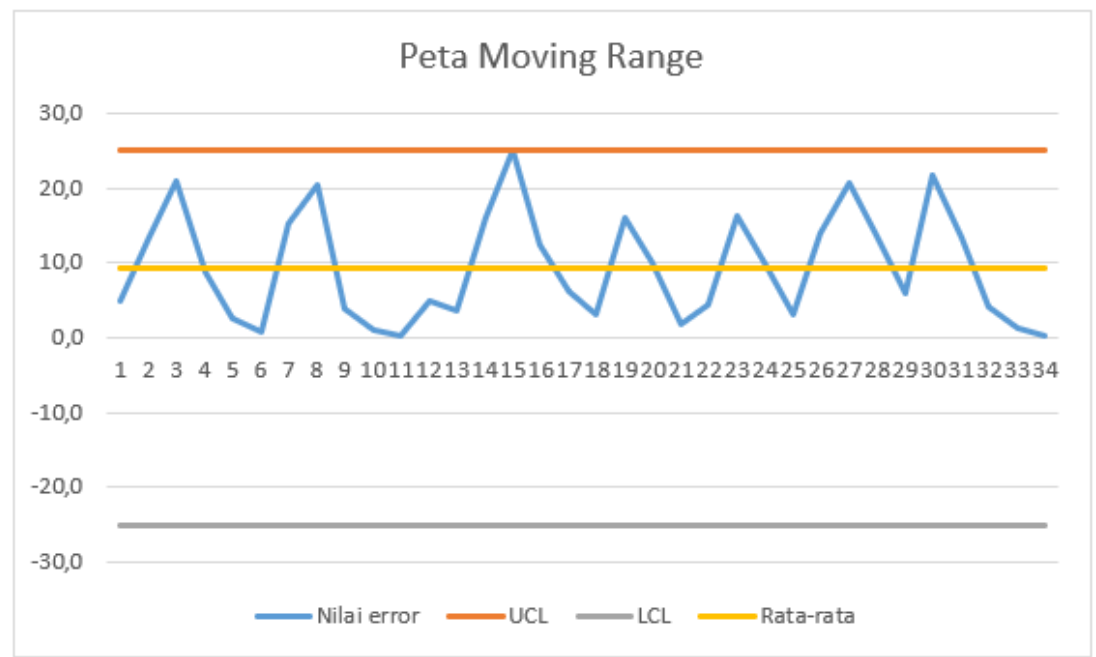

Gambar 6. Peta Kendali Moving Range Metode SES

Berdasarkan grafik diatas tampak bahwa tidak ada error yang melebihi nilai batas atas (UCL) dan batas bawah (LCL) yaitu sebesar +- 25,1 dan hasil peramalan dengan menggunakan SES dinyatakan valid sehingga dapat dijadikan acuan untuk melakukan forecast demand untuk beberapa periode kedepan.

e. Hasil peramalan

Setelah dilakukan uji validasi dan ternyata hasilnya dinyatakan valid, maka metode yang terpilih yakni metode Single Exponential Smoothing (SES) dapat digunakan untuk memprediksi permintaan untuk beberapa periode kedepan. Berikut merupakan hasil peramalan untuk 12 bulan kedepan dengan menggunakan metode Single Exponential Smoothing (SES):

Tabel 2. Hasil Peramalan Metode SES

\begin{tabular}{|c|c|c|}
\hline Periode & Hasil Peramalan & Pembulatan \\
\hline 1 & 30,046 & 31 \\
\hline 2 & 30,046 & 31 \\
\hline 3 & 30,046 & 31 \\
\hline 4 & 30,046 & 31 \\
\hline 5 & 30,046 & 31 \\
\hline 6 & 30,046 & 31 \\
\hline 7 & 30,046 & 31 \\
\hline 8 & 30,046 & 31 \\
\hline 9 & 30,046 & 31 \\
\hline 10 & 30,046 & 31 \\
\hline 11 & 30,046 & 31 \\
\hline 12 & 30,046 & 31 \\
\hline \multicolumn{3}{|c|}{ Sumber: Olah Data, 2019} \\
\hline
\end{tabular}

Jadwal Induk Produksi (JIP)

Dari hasil peramalan yang telah didapatkan dengan menggunakan metode SES (Single Exponential Smoothing), digunakan sebagai data permintaan untuk tahun berikutnya, yang 
kemudian digunakan sebagai Jadwal Induk Produksi (JIP). Berikut merupakan data JIP dalam periode bulan:

Tabel 3. Jadwal Induk Produksi

\begin{tabular}{|l|c|c|c|c|c|c|c|c|c|c|c|c|}
\hline Periode & 1 & 2 & 3 & 4 & 5 & 6 & 7 & 8 & 9 & 10 & 11 & 12 \\
\hline Pembulatan & 31 & 31 & 31 & 31 & 31 & 31 & 31 & 31 & 31 & 31 & 31 & 31 \\
\hline
\end{tabular}

\section{Material Requirement Planning (MRP)}

MRP digunakan untuk melakukan perencanaan dan pengendalian item barang (komponen) yang tergantung (dependent) pada item-item yang ada ditingkat/level yang lebih tinggi. Jumlah item yang hendak diproduksi pada tingkat level yang lebih tinggi menentukan jumlah item yang akan dibuat atau diperlukan pada tingkat dibawahnya. Selain Bill of Material dan Jadwal Induk Produksi, dibutuhkan catatan persediaan yang dimiliki oleh perusahaan dan lead time dari setiap bahan baku yang dibutuhkan sebagai input MRP.

Input MRP adalah sebagai berikut:

a. Bill of Material

Bill of material berisi informasi atas semua material, komponen, atau subassemblies yang diperlukan untuk menghasilkan masing - masing item akhir. BOM sebagai pengendali produksi merencanakan berapa banyak dari tiap item akhir harus tersedia pada waktu - waktu tertentu. Berikut ini merupakan gambar struktur Bill of Material dari produk kursi kayu bengkok dapat dilihat pada gambar 7.

b. Data persediaan dan leadtime

Data persediaan yang dikumpulkan dalam penelitian ini adalah data persediaan bahan baku yang digunakan untuk membuat kursi. Berikut ini merupakan data persediaan dan lead time dari masing - masing bahan baku kursi:

Tabel 4. Data Persediaan dan Leadtime

\begin{tabular}{|c|l|l|c|}
\hline No & \multicolumn{1}{|c|}{ Nama Material } & Persediaan & $\begin{array}{c}\text { Lead } \\
\text { time } \\
\text { (minggu })\end{array}$ \\
\hline 1 & Kayu mix jati \& mahoni & 2 kayu & 1 \\
\hline 2 & Kayu mix jati \& mahoni & 2 kayu & 1 \\
\hline 3 & Plitur & 3 liter & 1 \\
\hline 4 & Busa & 2 lembar & 1 \\
\hline 5 & Lem Fox 185 gram & 12 kaleng & 1 \\
\hline 6 & Kain & 2 lembar & 1 \\
\hline
\end{tabular}

c. Biaya pesan, biaya simpan, dan harga beli bahan baku

Biaya pembelian merupakan Harga per Unit yang diterapkan pada setiap transaksi yang berkaitan dengan pembatalan atau pemindahan Unit. Berikut ini merupakan biaya pembelian bahan baku pembuatan kursi kayu bengkok pada tabel 5 .

Tabel 5. Biaya Pembelian Bahan Baku Kursi

\begin{tabular}{|c|l|c|c|c|c|}
\hline \multirow{2}{*}{ No } & \multirow{2}{*}{ Nama Komponen } & \multicolumn{3}{|c|}{ Ukuran } & \multirow{2}{*}{ Harga Beli } \\
\cline { 3 - 5 } & & $\mathrm{p}$ & $\mathrm{l}$ & $\mathrm{t}$ & \\
\hline 1 & Kayu mix jati \& mahoni & 140 & 75 & 4 & $\mathrm{Rp} 190.000$ \\
\hline 2 & Kayu mix jati \& mahoni & 140 & 75 & 2,5 & $\mathrm{Rp} 150.000$ \\
\hline 3 & Plitur & \multicolumn{3}{|c|}{1} & $\mathrm{Rp} 155.000$ \\
\hline 4 & Busa & 200 & 100 & 5 & $\mathrm{Rp} 260.000$ \\
\hline 5 & Lem Fox 185 gram & \multicolumn{3}{|c|}{1} & $\mathrm{Rp} 18.500$ \\
\hline 6 & Kain & 8 & 1 & & $\operatorname{Rp~} 300.000$ \\
\hline
\end{tabular}


Tabel 6. Biaya Pesan Dan Biaya Simpan Bahan Baku Kursi

\begin{tabular}{|l|l|l|l|}
\hline No & Nama Komponen & Biaya Pesan & Biaya Simpan \\
\hline 1 & $\begin{array}{l}\text { Kayu mix jati \& } \\
\text { mahoni }\end{array}$ & $\operatorname{Rp~150.000}$ & $\mathrm{Rp} \mathrm{2.958,33}$ \\
\hline 2 & $\begin{array}{l}\text { Kayu mix jati \& } \\
\text { mahoni }\end{array}$ & $\mathrm{Rp} \mathrm{150.000}$ & $\mathrm{Rp} \mathrm{2.662,50}$ \\
\hline 3 & Plitur & $\mathrm{Rp} \mathrm{25.000}$ & $\mathrm{Rp} \mathrm{221,88}$ \\
\hline 4 & Busa & $\mathrm{Rp} 60.000$ & $\mathrm{Rp} \mathrm{2.130,00}$ \\
\hline 5 & $\begin{array}{l}\text { Lem Fox 185 } \\
\text { gram }\end{array}$ & $\mathrm{Rp} 15.000$ & $\mathrm{Rp} \mathrm{310,63}$ \\
\hline 6 & Kain & $\mathrm{Rp} \mathrm{50.000}$ & $\mathrm{Rp} \mathrm{887,50}$ \\
\hline
\end{tabular}

Biaya Pesan merupakan biaya yang terjadi karena adanya kegiatan pemesanan kepada vendor hingga barang sampai di gudang atau pengorganisasian untuk memulai produksi di dalam pabrik. Biaya ini meliputi biaya transportasi, biaya bongkar muat barang, biaya penerimaan dan pemeriksaaan barang, dan lain-lain. Berikut ini merupakan biaya pesan bahan baku pembuatan kursi kayu bengkok:

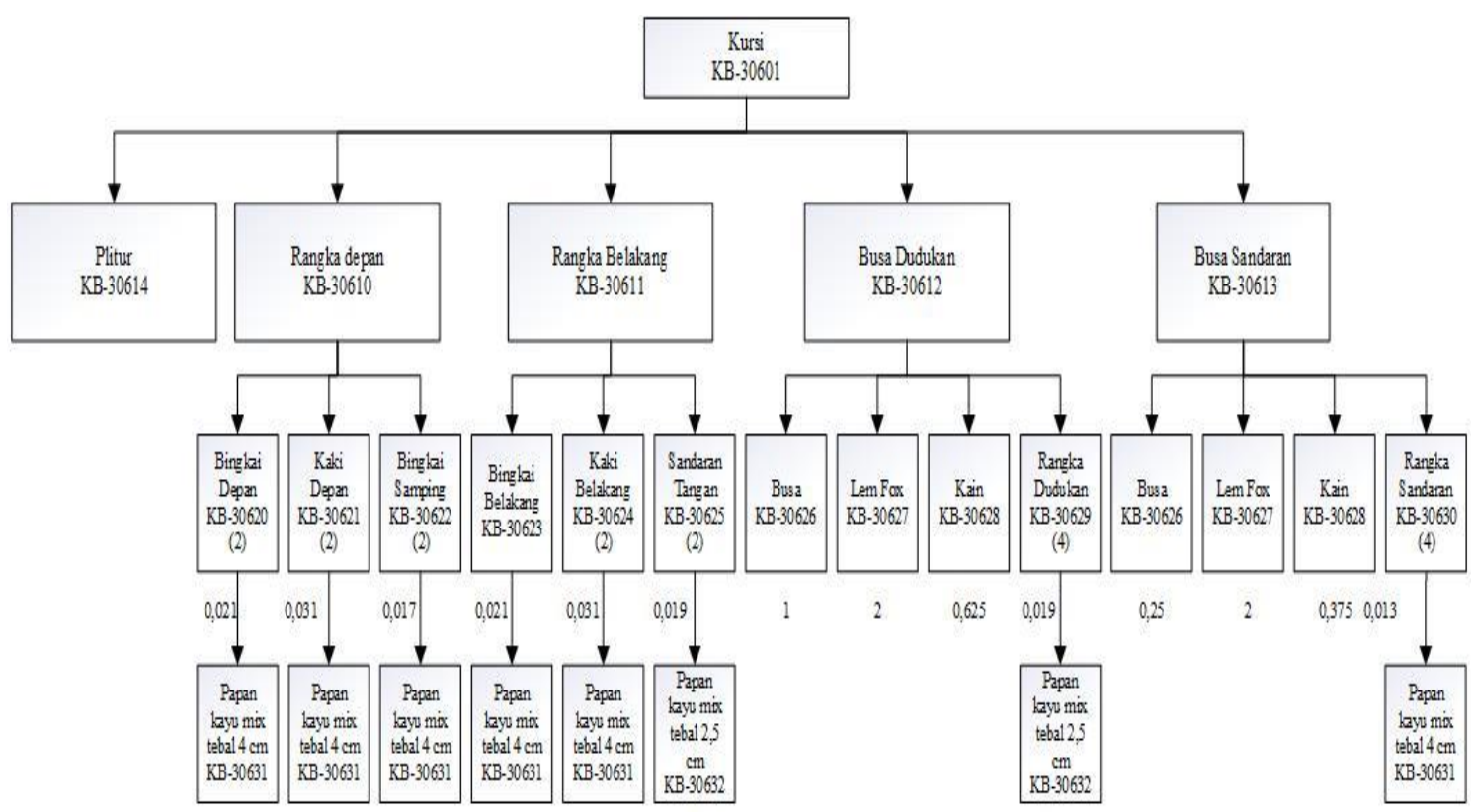

Gambar 7. BOM Kursi Kayu Bengkok

Biaya simpan merupakan biaya yang dikeluarkan berkaitan dengan diadakannya persediaan barang. Berikut ini merupakan biaya simpan bahan baku pembuatan kursi kayu bengkok:

Jadwal Induk Produksi bisanya dinyatakan dalam kaitan dengan kebutuhan time-phased yaitu penghitungan waktu penyelesaian produk akhir dimana perhitungan berjalan mundur untuk menentukan kapan setiap komponen harus dipesan. Kenaikan waktu yang ditemukan untuk menjadi paling praktis adalah mingguan sehingga horizon perencanaan dapat berisikan beberapa periode perencanaan satu mingguan. Berdasarkan data JIP 12 bulan maka akan dikonversi menjadi 52 periode dalam minggu. Berikut ini merupakan Jadwal Induk Produksi dalam mingguan yang digunakan dalam perhitungan MRP: 
Tabel 7. JIP Dalam Minggu

\begin{tabular}{|l|c|c|c|c|c|c|c|c|c|c|c|c|c|c|c|c|c|c|c|c|}
\hline Periode & 1 & 2 & 3 & 4 & 5 & 6 & 7 & 8 & 9 & 10 & 11 & 12 & 13 & 14 & 15 & 16 & 17 & 18 & 19 & 20 \\
\hline Kebutuhan & 6 & 7 & 7 & 8 & 7 & 7 & 7 & 8 & 7 & 7 & 7 & 8 & 6 & 7 & 7 & 8 & 7 & 7 & 7 & 8 \\
\hline
\end{tabular}

\begin{tabular}{|l|c|c|c|c|c|c|c|c|c|c|c|c|c|c|c|c|c|c|}
\hline Periode & 21 & 22 & 23 & 24 & 25 & 26 & 27 & 28 & 29 & 30 & 31 & 32 & 33 & 34 & 35 & 36 & 37 & 38 \\
\hline Kebutuhan & 7 & 7 & 7 & 8 & 6 & 7 & 7 & 8 & 7 & 7 & 7 & 8 & 7 & 7 & 7 & 8 & 6 & 7 \\
\hline
\end{tabular}

\begin{tabular}{|l|c|c|c|c|c|c|c|c|c|c|c|c|c|c|c|}
\hline Periode & 39 & 40 & 41 & 42 & 43 & 44 & 45 & 46 & 47 & 48 & 49 & 50 & 51 & 52 & Total \\
\hline Kebutuhan & 7 & 8 & 7 & 7 & 7 & 8 & 7 & 7 & 7 & 8 & 6 & 7 & 7 & 8 & 143 \\
\hline
\end{tabular}

Dalam merencanakan dan mengendalikan persediaan bahan baku pada CV Adil, penulis menggunakan metode MRP. Adapun Lot Size yang digunakan untuk menghitung kebutuhan tiap itemnya adalah Lot-for-Lot (LFL), Economic Order Quantity (EOQ), dan Periodic Order Quantity (POQ). Dari data Jadwal Induk Produksi maka dapat dihitung jumlah kebutuhan tiap bahan baku dimasa yang akan datang dengan menggunakan data dari Bill of Material (BOM).

\section{Perhitungan MRP \\ Item level 0}

Item level 0 yaitu produk kursi kayu bengkok dihitung dengan menggunakan metode LFL, karena produk kursi kayu bengkok tidak ada biaya pesan dan biaya simpan sehingga tidak dapat dihitung menggunakan metode $\mathrm{EOQ}$ dan $\mathrm{POQ}$.

Item level 1

Item level 1 terdiri dari Rangka Depan, Rangka Belakang, Busa Sandaran, Busa Dudukan dan Plitur. Rangka Depan, Rangka Belakang, Busa Sandaran, dan Busa Dudukan dihitung dengan menggunakan metode LFL, karena item-item tersebut tidak ada biaya pesan dan biaya simpan sehingga tidak dapat dihitung menggunakan metode EOQ dan $\mathrm{POQ}$.

Item plitur dihitung dengan menggunakan metode LFL, EOQ dan POQ. plitur yang merupakan bahan baku pembuatan kursi dengan kebijakan beli sehingga terdapat biaya pesan dan biaya simpan. Item plitur inilah yang digunakan untuk menentukan metode terbaik dan menentukan metode MRP untuk item level selanjutnya. Berikut ini perbandingan biaya menggunakan metode LFL, EOQ dan POQ:

Tabel 8. Perbandingan Biaya Pada Plitur
\begin{tabular}{|l|l|l|}
\hline No & Metode & Total Biaya \\
\hline 1 & LFL & Rp 64.995 .000 \\
\hline 2 & EOQ & Rp 62.557 .097 \\
\hline 3 & POQ & Rp 58.299 .766 \\
\hline
\end{tabular}

Tabel diatas merupakan tabel rekap biaya pembelian dengan 3 teknik lotting yaitu Lot for Lot (LFL), Economic Order Quantity (EOQ), dan Periodic Order Quantity (POQ). Dari perhitungan diatas didapat bahwa teknik lotting yang mengeluarkan biaya paling minimum adalah teknik POQ dengan biaya yaitu $\mathrm{Rp} 58.299 .766,00$. Jadi, untuk perencanaan material pada level berikutnya yaitu level 2 dan 3 menggunakan metode POQ. Karena karakteristik dan leadtime hampir sama sehingga perhitungan selanjutnya bisa dianggap sama dengan level 1.

Berdasarkan perhitungan MRP yang telah dilakukan, perbandingan biaya antara metode terpilih yaitu metode $P O Q$ dengan perusahaan dapat dilihat pada table 10.

Tabel 10, merupakan tabel perbandingan biaya dengan menggunakan metode POQ dan biaya yang dikeluarkan perusahaan. Dari perhitungan total biaya tersebut, dapat diketahui bahwa penggunaan metode MRP dengan teknik lot sizing POQ dapat meminimalkan pengeluaran perusahaan dalam pengadaan material dengan menghemat biaya sebesar $18,9 \%$ atau sekitar Rp 81.649.533,00. POQ menjadi metode yang terbaik yang dapat diterapkan di CV Adil Ambarawa dalam melakukan perencanaan dan pengendalian bahan baku. 
Tabel 9. Perbandingan Biaya Metode POQ Dengan Perusahan

\begin{tabular}{|c|c|c|c|}
\hline \multirow{2}{*}{ No } & \multirow{2}{*}{ Material } & \multicolumn{2}{|c|}{ Total Biaya } \\
\hline & & $\mathrm{POQ}$ & Perusahaan \\
\hline 1 & Plitur & Rp $\quad 58.299 .766$ & Rp 71.600 .000 \\
\hline 2 & Busa & Rp 122.442 .463 & Rp 150.220.000 \\
\hline 3 & Lem Fox 185 gram & $\begin{array}{ll}\text { Rp } & 27.938 .288\end{array}$ & $\begin{array}{ll}\mathrm{Rp} & 33.295 .000\end{array}$ \\
\hline 4 & Kain & Rp 112.169.188 & Rp 135.900.000 \\
\hline 5 & Kayu mix $4 \mathrm{~cm}$ & Rp $\quad 21.115 .405$ & Rp $\quad 29.350 .000$ \\
\hline 6 & Kayu mix $2,5 \mathrm{~cm}$ & Rp $\quad 7.550 .358$ & Rp 10.800 .000 \\
\hline & Total & Rp 349.515.467 & $\operatorname{Rp} 431.165 .000$ \\
\hline
\end{tabular}

\section{Kesimpulan}

Dari hasil pengolahan data serta analisis yang dilakukan, maka didapatkan kesimpulan yaitu merancang perencanaan dan pengendalian bahan baku kursi kayu bengkok dengan menggunakan metode Material Requirement Planning (MRP) membuat CV. Adil Ambarawa mampu menentukan perencanaan kebutuhan dan jadwal pembelian bahan baku secara tepat dan jelas sehingga hal ini mampu mengurangi resiko terjadinya stock out material maupun over stock. Perhitungan MRP yang dilakukan menggunakan tiga metode yaitu Lot for Lot (LFL), Economic Order Quantity (EOQ), dan Periodic Order Quantity (POQ). Dari perbandingan total biaya tersebut, dapat diketahui bahwa penggunaan metode MRP dengan teknik lot sizing POQ dapat menghemat pengeluaran perusahaan untuk pengadaan material sebesar $18,9 \%$ sehingga $\mathrm{POQ}$ menjadi metode yang terbaik yang dapat diterapkan di CV Adil dalam melakukan perencanaan dan pengendalian bahan baku.

Dengan mengacu pada hasil proses pengolahan data, dapat disimpulkan bahwa metode Material Requirement Planning (MRP) dapat diterapkan pada perusahaan. Untuk teknik lotting sendiri, teknik yang paling tepat dapat diterapkan pada CV Adil Ambarawa adalah metode Periode Order Quantity (POQ) karena pada metode $\mathrm{POQ}$ menggunakan perhitungan dengan mempertimbangkan biaya pesan dan biaya simpan, serta menunjukkan biaya jumlah periode pemesanan dibandingkan dengan jumlah pemesanan pada unit - unitnya. Selain itu, metode POQ merupakan pengembangan dari metode $E O Q$ dengan permintaan yang tidak seragam dalam beberapa periode seperti data permintaan di CV Adil Ambarawa.

\section{Referensi}

Assauri, Sofyan, 2008, Manajemen Pemasaran, edisi pertama, cetakan kedelapan,

Gaspersz, Vincent. 1998. "Production Planning and Inventory Control Berdasarkan 72 Pendekatan Sistem Terintegrasi MRP II dan JIT Menuju Manufacturing 21". Jakarta: Gramedia Pustaka Utama.

Handoko, T. Hani, 2003, Manajemen Personalia dan Sumber Daya Manusia, Yogyakarta, BPEEYogyakarta

Heizer, Jay dan Barry Render (2005). Manajemen Operasi, Edisi 7. Jakarta: Salemba 4.

Hendra K. 2009. "Manajemen Produksi: Perencanaan dan Pengendalian Produksi". Edisi 4. Penerbit Andi: Yogyakarta.

Makridakis, S.C., Wheelwright, dan Victor E., Mc Gee. 1998. "Metode dan Aplikasi Peramalan". Edisi Pertama. Binarupa Aksara: Jakarta.

Nasution, A. 2003. "Perencanaan dan Pengendalian Produksi”. Guna Widya: Surabaya. Penerbit: Raja Grafindo, Jakarta

Purnomo Hadi., 2004, "Pengantar Teknik Industri", Graha ilmu, Yogyakarta.

Rangkuti, Fredy. 1995. "Manajemen Persediaan Aplikasi dibidang Bisnis". Raja Grafindo Persada: Jakarta

Tampubolon, P. 2004. "Manajemen Operasi (Operation Management)". Ghalia Indonesia: Jakarta.

Yamit, Zulian. 1998. “Manajemen Produksi dan Operasi”. BPFE UII: Yogyakarta. 